\title{
BMJ Open How congenital Zika virus impacted my child's functioning and disability: a Brazilian qualitative study guided by the ICF
}

\author{
Taynah Neri Correia Campos (D) , ${ }^{1}$ Veronica Schiariti, ${ }^{2}$ Melissa Gladstone (D) , ${ }^{3}$ \\ Adriana Melo, ${ }^{4}$ Jousilene Sales Tavares, ${ }^{4}$ Adriana Gomes Magalhães, ${ }^{5}$ \\ Egmar Longo ${ }^{6}$
}

To cite: Campos TNC, Schiariti V, Gladstone M, et al. How congenital Zika virus impacted my child's functioning and disability: a Brazilian qualitative study guided by the ICF. BMJ Open 2020;10:e038228. doi:10.1136/ bmjopen-2020-038228

- Prepublication history and additional material for this paper is available online. To view these files, please visit the journal online (http://dx.doi.org/10. 1136/bmjopen-2020-038228).

Received 10 April 2020 Revised 20 0ctober 2020 Accepted 30 October 2020

Check for updates

(C) Author(s) (or their employer(s)) 2020. Re-use permitted under CC BY-NC. No commercial re-use. See rights and permissions. Published by BMJ.

For numbered affiliations see end of article.

Correspondence to

Dr Egmar Longo;

egmarlongo@yahoo.es

\section{ABSTRACT}

Introduction The Zika virus outbreak in Brazil has had devasting social, medical and financial consequences for families. Both researchers and clinicians are measuring longer-term outcomes to understand the impact of the Zika on child development, functioning and disability. Outcomes and tools used to measure them are very varied and we are unclear how meaningful they are to families and children. This study aimed to identify the parents' perspectives on relevant areas of functioning and disability that should be included as outcome measures for children with congenital Zika syndrome (CZS), as guided by the International Classification of Functioning, Disability and Health (ICF).

Methods This qualitative study included parents or caregivers of children aged $0-5$ years with confirmed CZS from two states in northeastern Brazil. Interviews were conducted using focus groups. Content mapping followed the WHO's ICF linking rules. Three raters analysed the content using NVivo V.11.

Results Thirty-two caregivers participated in six focus groups, $88 \%$ were mothers with an average age of 30 years. Most children were male (59\%) and all were level $\mathrm{V}$ (severe) to on the Gross Motor Function Classification System (GMFCS). Overall, 825 themes were mapped to 36 ICF categories. Although parents mentioned areas across all ICF domains, they reported that areas of mobility, eating and recreation were most relevant for them. In addition, environmental factors were highly identified as barriers, specifically services, policies and access to assistive devices. The most predominant facilitators within the environment were; immediate family support, kind relationships with therapists and support from the extended family.

Conclusions Although parents emphasised issues related to mobility, their greatest concerns involved environmental factors, such as access and quality of health and social services, systems and policies. These results reinforce the importance of including parents' perspectives when selecting or developing outcome measures for CZS.

\section{INTRODUCTION}

The Zika virus (ZIKV) was identified in Brazil at the beginning of 2015. During this time,
Strengths and limitations of this study

- This is the first International Classification of Functioning, Disability and Health-based qualitative study describing caregivers' perceptions on relevant areas of function in children with congenital Zika syndrome in Brazil.

- Few studies have previously undertaken research to understand parent's views on the issue of what outcome measures should be considered in neurodevelopmental disorders.

- We had limited representation of men within our sample as the main caregiver was predominantly women.

- Our study was limited in terms of numbers of participants and region in Brazil, limiting the generalisability of our study.

rates of microcephaly and other congenital brain abnormalities increased, suggesting a causal relationship between the two. ${ }^{1}$ Since then, clinical reports have documented the teratogenic effect of ZIKV in pregnant women, particularly when infected in the first trimester. ${ }^{2-4}$ The most prominent anomalies for children with congenital ZIKV is microcephaly, but other manifestations such as, spasticity, seizures, eating difficulties, irritability, ocular abnormalities, hearing loss, calcifications, cortical disorders and ventriculomegaly have been described. ${ }^{5-7}$ There is still no clear definition of exactly what is included in congenital Zika syndrome (CZS). As a result, surveillance studies are underway to identify the wider spectrum of congenital malformations, which may be associated with ZIKV infection. ${ }^{8}$

A precise estimate of ZIKV infection incidence is difficult to determine due to variations in case ascertainment between countries and only a small number of children identified 
with manifestations of the more severe congenital ZIKV syndrome. ${ }^{10}$ There are currently 3406 confirmed cases of children with microcephaly and/or other neurological signs due to CZS in Brazil, with a further 2596 cases under investigation. ${ }^{11}$

Given the severity of the syndrome, the scientific community has mobilised efforts to understand the mechanisms of this health condition and to measure long-term health and neurodevelopmental outcomes of children with this condition. Presently, a large variety of heterogeneous tools and outcomes are being used, often which causes confusion and lack of ability to conduct meta-analyses and syntheses of data. Furthermore, most tools chosen are those chosen by epidemiologists and researchers who may have little understanding of the what is most relevant to parents and families with children with this condition. Primarily, tools to measure child development are used; not always that relevant when functioning for these children may be very limited. As such, creating a standardised core outcome set (COS) for CZS will reduce the heterogeneity of the studies and further enable clearer synthesis and data sharing between studies. ${ }^{12}$

The Core Outcomes Measures in Effectiveness Trials is an initiative aimed at identifying and creating a core set of outcomes for any clinical health situation. This is often conducted through a process of systematic reviews of outcomes measured, consensus work as well as the involvement of families who support the development of these outcomes in order to ensure that researchers consider outcomes that are most relevant and appropriate to the patient's needs. ${ }^{13} 14$ As part of COS development, a framework is usually used to enable outcomes to be classified and considered for finalisation in a COS. In the case of neurodisability and neurodevelopmental disorders, a helpful framework can be the International Classification of Functioning, Disability and Health (ICF) which provides a standard language and framework for health states. ${ }^{14}$ The ICF includes both functions and structure of the body and activities and participation of the child and can be used as a guiding framework providing a common language for describing the dynamic interaction between the person functional abilities and the role of the environment. ${ }^{15}$

Currently, there is no COS for children with CZS. To fill this gap, we aim to develop a COS for children with Zika and other congenital infections. This project is coordinated by the University of Liverpool in partnership with the University of Victoria (Canada) and Federal University of Rio Grande do Norte-UFRN-FACISA (Brazil). This paper describes a qualitative study that is part of the first phase of the COS for CZS project. ${ }^{16}$ The specific objective of this qualitative study is to identify the parents' perspectives on relevant areas of functioning and disability which should be included as outcome measures for children with CZS, guided by the ICF.

\section{METHODS}

This study used a qualitative methodology with an exploratory approach through focus groups. We chose to use a qualitative approach as it enables investigation and an in-depth understanding of the perspectives and experiences of parents/caregivers of children with CZS. Focus groups, in particular, provide the potential to explore and clarify points of view and reveal dimensions of understanding which would be less easily accessible in other data collection formats. ${ }^{17} 18$

Parents/guardians signed a Consent Form after being provided with an information sheet which was read out to them. Parents also signed consent for voice recording and use of images.

Participants with important common characteristics were purposively selected by members of the research team, through active search by phone call or direct personal approach. The inclusion criteria included: (1) being parents/caregivers of children with confirmed diagnosis of CZS by PCR or presumed diagnosis based on obstetric ultrasound, transfontanellar ultrasound, CT and MRI, (2) child with congenital CZS aged 0-5years and (3) living in the area covered by the study (states of Rio Grande do Norte and Paraíba) and attending the respective rehabilitation services.

The rehabilitation centres are public services linked to research institutions and higher education in the region. This study did not include parents whose children had congenital syndromes due to other aetiologies.

All parents responded to a sociodemographic questionnaire, applied by the researchers prior to the focus groups with information about; their relationship with the child, marital status, age, income, government benefit, education, housing and self-reported health, in addition to information from children about gender, age, mobility, rehabilitation, frequency day care centres or schools, and difficulties with vision, hearing, sleep and epilepsy. This questionnaire was to ensure good understanding prior to rolling it out to all respondents. Two research assistants were involved in the data collection. In each centre, the physiotherapist who accompanied the children classified their motor abilities using the GMFCS. This is an age-specific scheme designed for children with cerebral palsy (CP) based on five levels of gross motor function, ranging from level I (most able) to level $\mathrm{V}$ (least able $)^{19}$ and provided some clear information on the severity of the children whose parents took part in the study. The study flow chart can be viewed in figure 1 . We used the Consolidated criteria for Reporting Qualitative research guidelines to guide us with our study methodology and write up.

The focus groups were carried out between September 2018 and January 2019, by research assistants (TCC and EL), trained both in qualitative studies and in conducting focus groups. We continued to do focus groups until saturation was reached-where testimonies became repetitive, predictable and were not providing any additional information. Saturation was achieved by the sixth group. We did not exceed six parents/caregivers per group in order to enable effective participation of the participants and appropriate discussion of themes. Of the 36 parents identified and invited to the study, 32 agreed to participate. 


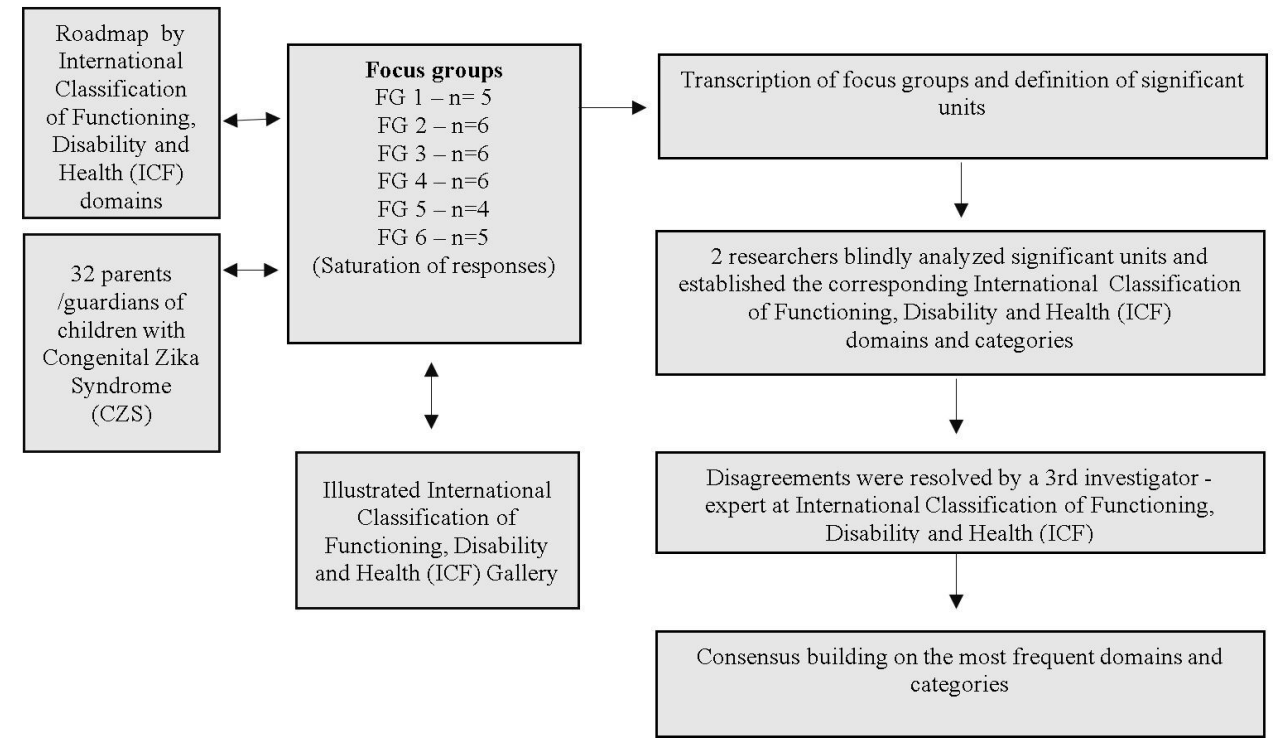

Figure 1 Study flow chart. ICF, international classification of functioning, disability and health.

A questionnaire adapted from a previous ICF-based qualitative study was used to conduct the focus group, covering the different ICF domains (see online supplemental material 1). ${ }^{20}$ Visual tags were produced with images from the ICF illustrated gallery (see online supplemental material 2$)^{21}$ to assist in understanding the concepts, as studies indicate that visualisation has the potential to support data production during the qualitative interview process. ${ }^{22}$ The duration of the focus groups ranged from 60 to $90 \mathrm{~min}$. The participants were given a therapeutic toy developed by research team at the end of the groups, called 'fun fishing', in order to thank the parents for participating in the study. They were encouraged by the professional team to use it as a therapeutic toy for stimulation of their children at home and to promote fun. All groups were recorded and later transcribed in full. Names of participants and any identifying characteristics were excluded from the transcripts. The transcribed content was analysed by three researchers experienced in qualitative research (TCC and EL). They split the content into significant units with using NVivo software, V.1.0 (QSR International, 2019), and associated them with each ICF domain and category using the WHO's linking rules ${ }^{23}$ as follows: TCC and EL, trained in ICF, performed a blind reading of the content and established the ICF domain and category for each significant unit of the interview to which it was judged to be relevant versus, a specialist in ICF and with extensive experience in childhood disability, analysed the disagreements of the two researchers, establishing consensus in relation to the domain/category of the ICF regarding the significant units.

Next, the content was analysed by the researchers who interpreted the data through an inductive and deductive analysis process based on a permanent dialogue throughout the process to ensure consistency and reliability of the interpretations. Any verbatim which did not exceed 'five mentions' was discarded as it was felt not to be representative enough of the data. The frequency of each ICF category in the statements of parents/caregivers was used as a parameter to determine the order of importance of ICF domains/categories. After this process, the content was translated from Brazilian Portuguese into English by a bilingual member of the research team and the content checked by two others, to ensure that there was no loss of meaning.

Aspects of credibility, transferability, reliability and confirmability were considered during all stages in order to guarantee the quality of the qualitative research. ${ }^{24}$ Credibility was ensured by thoroughly conducting six focus groups until saturation was reached, with subsequent blind analysis, review and triangulation, and then consensus being reached after meetings and debates regarding the interpretation of results. The researchers have robust training in the area of childhood disabilities and in the use of the ICF for neurodisabilities. Transferability occurred through observation of the rigour to which the research group stopped to describe how the data was obtained through the focus groups, the selection and description of the sample, which in this case involved the participants. Reliability was guaranteed by detailing the data collection processes, presenting the multiple steps followed by the researchers, and showing how the pair analysis and data interpretation took place. A measure of reliability through using the kappa statistic was also used to verify the agreement between the judges, with results indicating almost perfect agreement (0.916) considering 95\% CIs. Finally, verification was achieved through a peer discussion of the data at each stage of the analysis by the research team.

\section{Patient and public involvement}

Families were not involved in the design, recruitment or conduct of the study. However, the results will be presented to families, professionals and managers at each 


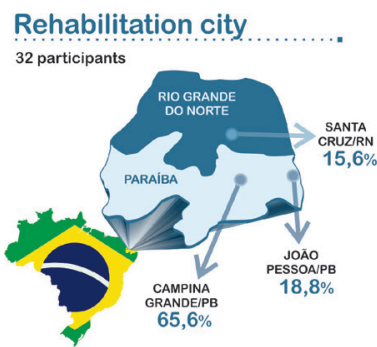

Rehabilitation

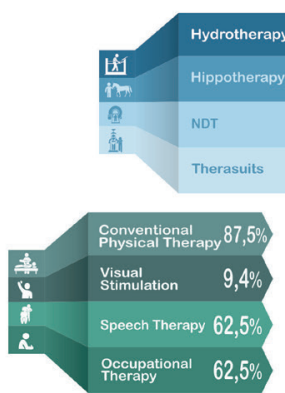

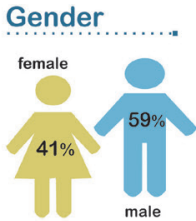

Problems

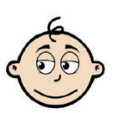

Vision $68,8 \%$
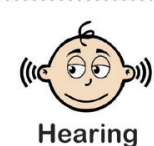

$31,3 \%$

.
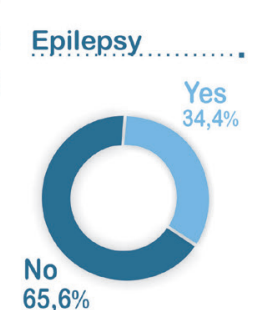

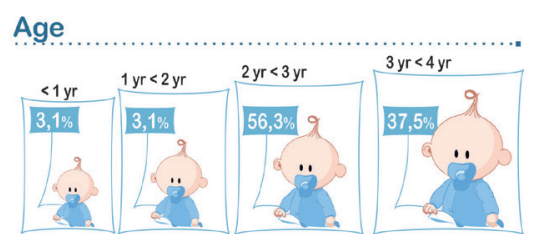

Siblings

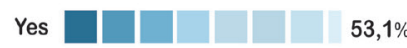

No $\square=46,9 \%$

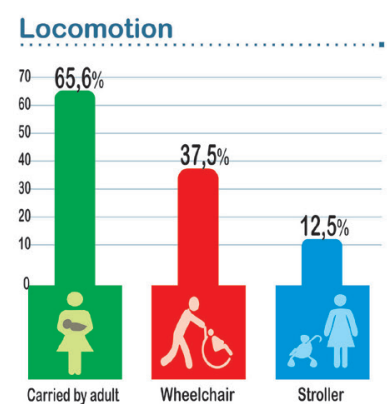

Figure 2 Sociodemographic data of children.

participating centre, with a view to discussing strategies to meet the needs of children with CZS and their families.

\section{RESULTS}

Six focus groups were conducted with 32 caregivers of children with severe neurodevelopmental disorders associated with CZS. Information related to children can be found in figure 2 and the characteristics of families are in figure 3 . The average age of the children was 32.5 $(\mathrm{SD}=6.2)$ months, with a predominance of males, all with severe motor impairment on, the GMFCS. Although none of the children walked, only $37.5 \%$ of them had a wheelchair.

Thirty-six categories of the ICF were identified, as demonstrated in figure 4 (personal factors were expressed only minimally). This figure represents the parents' perspectives on relevant areas of functioning and disability of their children.

The parents mentioned relevant areas that covered all ICF domains, but a greater diversity of categories was observed in the domains of activities and participation and body functions. However, the environmental factors

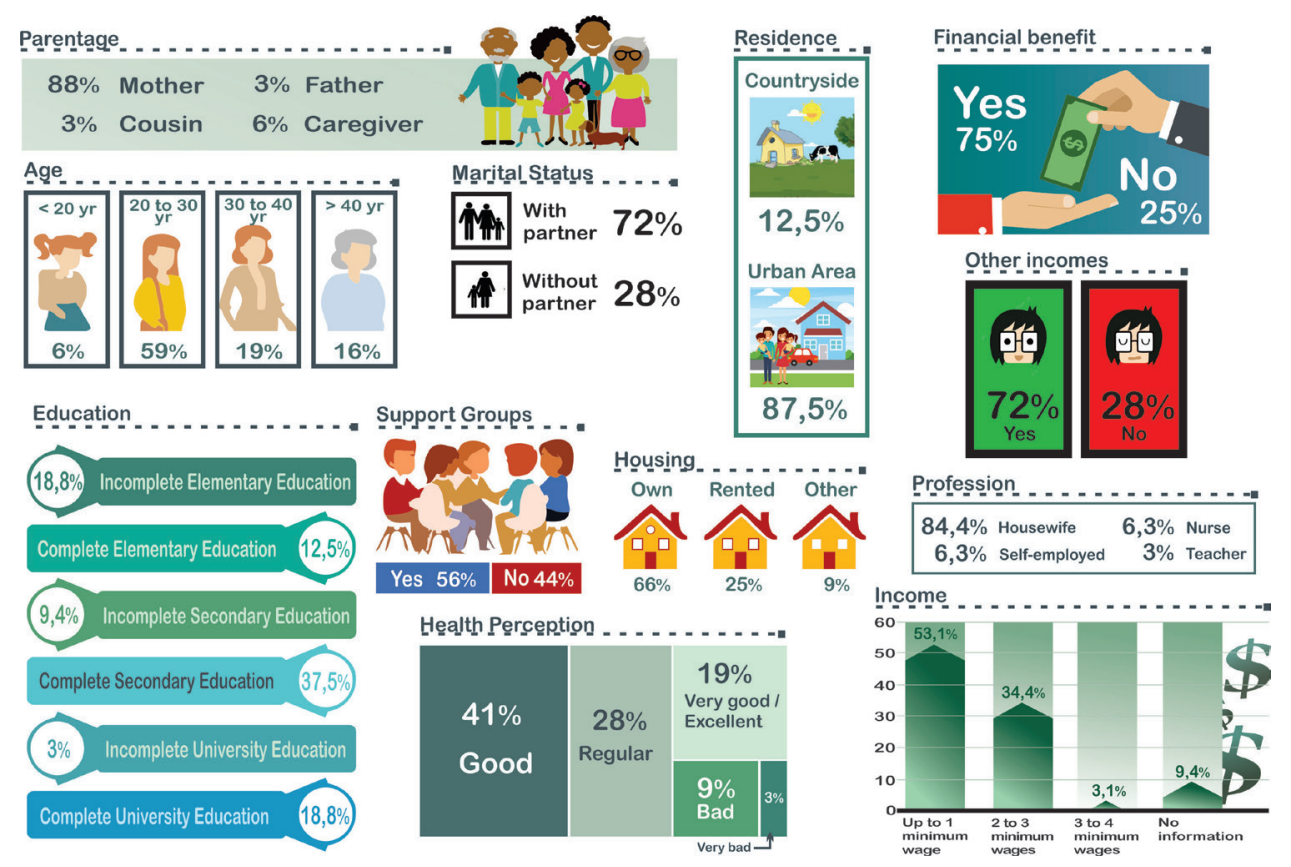

Figure 3 Sociodemographic data for parent/caregivers. 


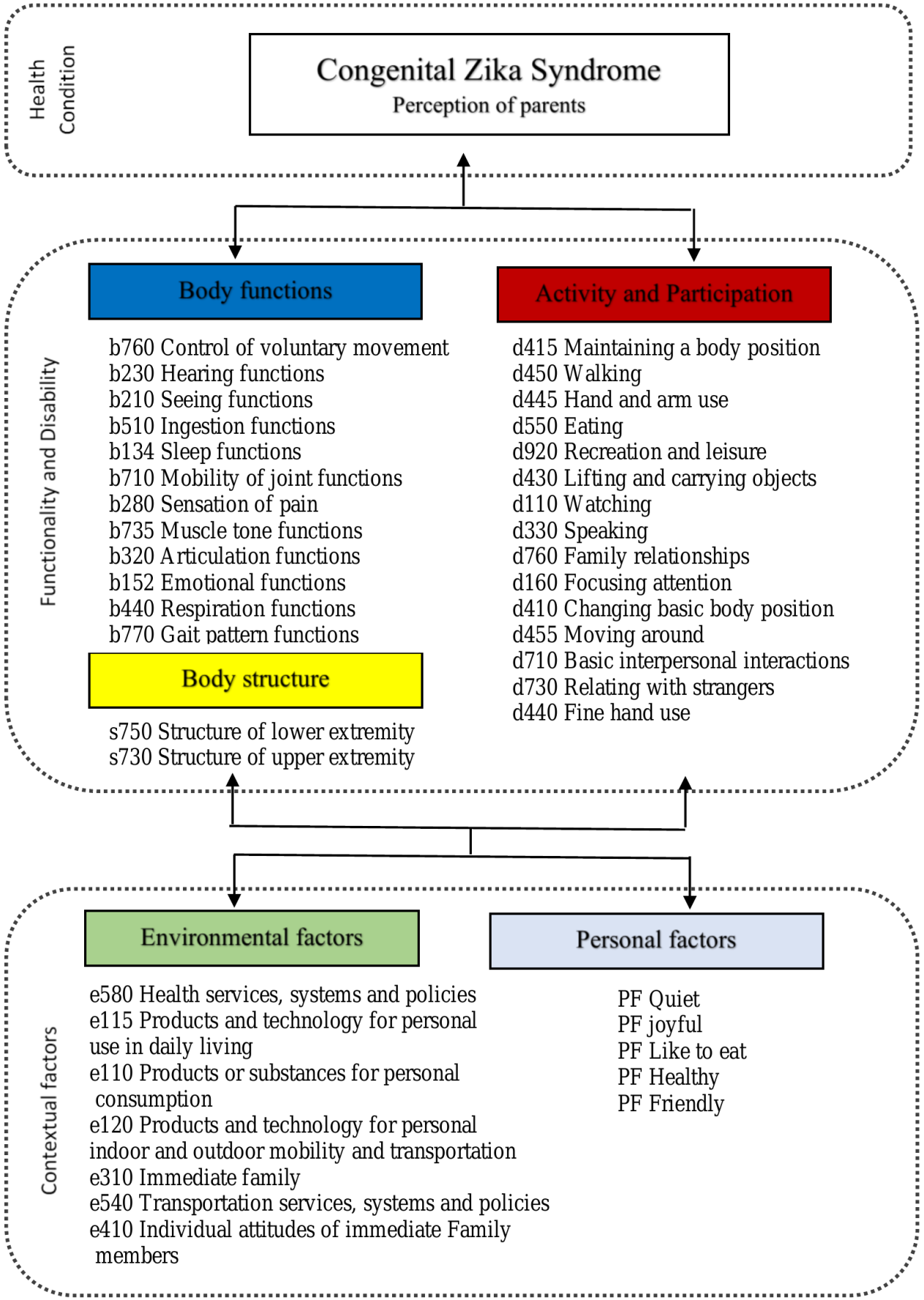

Figure 4 ICF categories representing the parents' perspective. ICF, international classification of functioning, disability and health.

domain led the ranking of 12 categories, as can be seen in table 1.

Table 2 shows the distribution of categories related to the environmental factors domain in detail.

Among the categories, health services, systems and policies (e580) was the barrier most expressed by parents, receiving 59 mentions. This category includes the prevention and treatment of health problems, the provision of rehabilitation services and the promotion of a healthy lifestyle. The following verbatim demonstrates a mother's desire to have access to rehabilitation services in her own city.
Also that in Alagoas state has been the same possibilities that here in Campina, to don't need to move from one place to other, it's so complicated spend 3 months here, searching treatment that there it should have. I don't know they can't leave this treatment there, to every states have, for us don't need to move a lot to do a treatment. For them could at least sit, maintain their trunk, catch and walk. Mother 20.

Other barriers reported in this area included; lack of information or professionals specialised in the management of CZS and the difficulty in transport to travel to 
Table 1 Table demonstrating the ranking of the 12 most frequent categories of the ICF mentioned by parents

\begin{tabular}{llll}
\multicolumn{2}{l}{ Category } & QTY & Domain \\
\hline $1^{\circ}$ & e580 Health services, systems and policies & 59 & Environmental factors \\
$2^{\circ}$ & b760 Control of voluntary movement functions & 37 & Body functions \\
$3^{\circ}$ & e115 Products and technology for personal use in daily living & 33 & Environmental factors \\
$4^{\circ}$ & d415 Maintaining a body position & 33 & Activities and participation \\
$5^{\circ}$ & e110 Products or substances for personal consumption & 31 & Environmental factors \\
$6^{\circ}$ & b230 Hearing functions & 31 & Body functions \\
$7^{\circ}$ & b134 Sleep functions & 31 & Body functions \\
$8^{\circ}$ & d450 Walking & 28 & Activities and participation \\
$9^{\circ}$ & e120 Products and technology for personal indoor and outdoor mobility and & 25 & Environmental factors \\
$10^{\circ}$ & b210 Seeing functions & 24 & Body functions \\
$11^{\circ}$ & d445 Hand and arm use & 23 & Activities and participation \\
$12^{\circ}$ & s750 Structure of lower extremity & 22 & Body structures \\
\hline
\end{tabular}

ICF, international classification of functioning, disability and health.

rehabilitation services in other larger cities. Examples of this are evidenced in the statements below.

I guess that it would help a lot if the access is facilitated, in our city, if I had physiotherapy in my city, sure I would go more often. Mother 03.

I would like that science produces medicines for this disease, because it is a new disease. Another thing, a great difficulty for me, is the absence of answers... you go to see a doctor with your child, and the doctor is stalling, he never tells you the reality... Mother 24 .

If our city would have treatment... moving is tiring. And if when we come, we were taken care of... We suffer from these experiences, some days I have spent many hours travelling... Mother 04.

Some parents pointed to assistive products and technologies as facilitators. They described how adapted or specially designed equipment improved the functioning of their children and contributed to greater participation;
For $\mathrm{E}^{*}$, to facilitate activities, first I put her glasses on... once I take her glasses off, her vision becomes worse... if I put the glasses on, she becomes much more animated. Mother 06.

The support of the nuclear family was expressed by participants of all focus groups as a major facilitator to their environment, as described below.

What helps? I have a lot of support from my husband and my sister. I live close to my sister... my parents don't live in the same city as me, but they always are present... Always... from the beginning they have been present. My family helps me a lot, and this helps me, when I want to go out and can't take her with me... I leave her with my sister. The family support, it's the main factor that helps me, because alone, it's hard. Mother 14.

Table 3 presents the categories referring to the activities and participation domain.

Table 2 Table of areas of the ICF considered important for parents within the area of environmental factors

\section{Environmental factors}

\begin{tabular}{|c|c|c|}
\hline e580 Health services, systems and policies & 59 & $33.0 \%$ \\
\hline e115 Products and technology for personal use in daily living & 33 & $18.4 \%$ \\
\hline e110 Products or substances for personal consumption & 31 & $17.3 \%$ \\
\hline e310 Immediate family & 16 & $8.9 \%$ \\
\hline e540 Transportation services, systems and policies & 9 & $5.0 \%$ \\
\hline
\end{tabular}

ICF, international classification of functioning, disability and health. 
Table 3 Table demonstrating areas of the ICF within activity and participation found as important to parents

\begin{tabular}{lrr}
\hline Activities and participation & & \\
\hline d415 Maintaining a body position & 33 & $14.5 \%$ \\
d450 Walking & 28 & $12.3 \%$ \\
d445 Hand and arm use & 23 & $10.1 \%$ \\
d550 Eating & 21 & $9.3 \%$ \\
d920 Recreation and leisure & 19 & $8.4 \%$ \\
\hline d430 Lifting and carrying objects & 15 & $6.6 \%$ \\
d110 Watching & 15 & $6.6 \%$ \\
\hline d330 Speaking & 12 & $5.3 \%$ \\
d760 Family relationships & 11 & $4.8 \%$ \\
\hline d160 Focusing attention & 11 & $4.8 \%$ \\
\hline d410 Changing basic body position & 9 & $4.0 \%$ \\
\hline d455 Moving around & 9 & $4.0 \%$ \\
\hline d710 Basic interpersonal interactions & 8 & $3.5 \%$ \\
\hline d730 Relating with strangers & 7 & $3.1 \%$ \\
\hline d440 Fine hand use & 6 & $2.6 \%$ \\
\hline Total & 227 & $100.0 \%$ \\
\hline
\end{tabular}

ICF, international classification of functioning, disability and health.

As shown in table 3 , the most often expressed categories were those related to movement of children, such as Maintaining a body position-d415, Walking-d450, and Hand and arm use-d445. Such aspects were pointed out by the parents as being responsible for limiting activity and restricting participation in daily activities, as evidenced in the statements below.

$\mathrm{M}^{*}$ has difficulty maintaining body position, when I put him in standing position supported by the wall, he can stay a long time. Sitting... he also doesn't sit alone, but if you put him in sitting... he stays there... He doesn't go from lying down position to sitting, but from sitting to lying, he can. Mother 15.

Eating... she holds it but doesn't know how put it in her mouth. Mother 01.

His major difficulties are to grasp things. He doesn't grasp and we need to put in his hands and then he holds it. If he needs to pick up something, he can not do it, but he holds and object if I open his hand for him Mother 08.

I guess it's so difficult for these children; they don't walk and don't sit yet. If, when I arrive in a place and it has a wheelchair I try and sit him in it, he still can not sit in it. Mother 17.

Finally, the areas of Body Function and Structure identified most by parents is shown in table 4 .

Control of voluntary movement-b760 was the most common category mentioned in the domain of functioning. Many parents expressed concerns about their child's voluntary movements (both simple and more
Table 4 Table demonstrating the categories of $D$ body functions and structures (within the ICF) identified as important by parents

\begin{tabular}{|lrr}
\hline $\begin{array}{l}\text { Body functions } \\
\text { b760 Control of voluntary movement } \\
\text { functions }\end{array}$ & 37 & $16.70 \%$ \\
\hline b230 Hearing functions & 31 & $14.00 \%$ \\
\hline b210 Seeing functions & 24 & $10.80 \%$ \\
\hline b510 Ingestion functions & 19 & $8.60 \%$ \\
\hline b134 Sleep functions & 31 & $14.00 \%$ \\
\hline b710 Mobility of joint functions & 18 & $8.10 \%$ \\
\hline b280 Sensation of pain & 16 & $7.20 \%$ \\
\hline b735 Muscle tone functions & 15 & $6.80 \%$ \\
\hline b320 Articulation functions & 10 & $4.50 \%$ \\
\hline b152 Emotional functions & 8 & $3.60 \%$ \\
\hline b440 Respiration functions & 7 & $3.20 \%$ \\
\hline b770 Gait pattern functions & 6 & $2.70 \%$ \\
\hline Total & 222 & $100 \%$ \\
\hline Body structures & 22 & $78.60 \%$ \\
\hline s750 Structure of lower extremity & $21.40 \%$ \\
\hline s730 Structure of upper extremity & 28 & $100 \%$ \\
\hline Total & & \\
\hline
\end{tabular}

ICF, international classification of functioning, disability and health.

complex) as well as their child's difficulties with coordination as well as use of their upper and lower limbs.

Control of movements... $L^{*}$ has a lot of difficulties, she can't lift her arm or her hand. With regards to her ability to move, she also has difficulties, she can't lift her arm and hand. She doesn't have a lot problems with her legs, but she can't move her body. Mother 24.

Parents also pointed out problems related to; Hearing functions-b230, Seeing functions-b210 and Sleep functions-b134.

Her hearing is only good on one side, on the other side, it doesn't work. We are doing a raffle to earn money to buy a device, because when she was examined it showed that she can hear with her left ear, but on the right, she doesn't hear anything. Mother 22.

About his vision, he doesn't see everything, his vision is low, he has difficulties. Father 01.

He has sleep difficulties, but when he falls on sleep, he sleeps the whole night. Mother 28.

With regard to 'body structure', the category relating to Structure of lower extremities-s750 most commonly emerged within our parent focus groups. Many parents described issues with foot positioning and how this prevented walking and standing. 
The knees, it is something that I guess she won't do. And her feet, to walk, that will be a great difficulty, because she has a dislocation. We don't know if she will walk or if she will need a wheelchair for the rest of her life. Mother 27.

About S*'s little foot... when I put him in standing position, his foot turns to the side. Mother 10 .

\section{DISCUSSION}

This pioneering research is the first to describe the perceptions of parents and caregivers regarding their understanding of the issues for their children with congenital CZS as placed within the ICF framework. Parents/caregivers highlighted the importance of environmental factors and motor function for their children with CZS. These factors must, therefore, be taken into account when constructing a recommended core set of outcomes to be measured in CZS. The use of the ICF as our guide for this study has enabled us to provide a holistic framework for considering perspectives that extend beyond the issues with body functions and structures for children with CZS.

Despite the number of new cases of CZS stabilising, the complex clinical presentation of CZS and its effect on children's health means that both standardised and individualised care is needed. ${ }^{25}$ Researchers need to consider a holistic approach to their measurement of outcomes when following these children. The diversity of needs of these children (and families) with CZS and neurodevelopmental disabilities is wide. ${ }^{26}$

Several ICF categories were identified by parents as very relevant and which must be considered and advocated for within the global context for the creation of a COS for CZS. This is particularly the case for researchers who will be measuring the effect of rehabilitation and support interventions for families. ${ }^{27}$ In particular, the importance that parents place on environmental factors for the wellbeing of their children demonstrates the real need to include this environmental context as an aspect to be assessed in the follow-up of children with CZS. ${ }^{28} 29$

Our study has demonstrated that the lack of trained professionals to support families is a major issue for parents that needs to be addressed. ${ }^{30}$ Furthermore, parents expressed a great need for information about the condition of their children. ${ }^{31}$ The Centers for Disease Control and Prevention has produced a pocket guide summarising paediatric guidelines on initial assessment and outpatient treatment for CZS. ${ }^{32}$ Resources such as this could be more often provided for parents, particularly if given in a caring and sensitive manner with space for parents to reflect and ask questions. It is clear that a carefully planned public health approach which targets the needs of parents and families and provides adequate care and support for children and families, is still lacking. ${ }^{33}$ Addressing the environmental issues which hinder many parents and families' every day functioning is the most crucial aspect of this, and the one that will make the most difference for families and children quality of life.
Many parents/caregivers in our study expressed a desire to receive treatment and support in a single place or city. Moving from place to place for services and different types of rehabilitation all the time, is a real barrier for families. Parents in our study signalled a definite need for reorganising health services in a way which would provide more of a 'one stop' approach for supporting them. This has been highlighted in other studies. ${ }^{35}$ Furthermore, lack of access to services (mainly due to distance, cost and lack of availability) was a massive issue for families of children with CZS. ${ }^{36}$ From our study, it is clear that services for support and rehabilitation in a single location would minimise problems of low attendance and/or avoidance of services. Lack of attendance interferes hugely with enabling good outcomes when using focused, contextbased and evidence-based rehabilitation. ${ }^{37}$

Parents who took part in our study voiced particular concerns around aspects of their children's movement. This permeated the domains of activities and participation, functions and body structure and was, of course, expressed as a limiting factor in their participation in daily and leisure activities. It was clear that parents were disappointed and desperate for a change in mobility of their children and had had little counselling about adaptations to support children in their daily lives through other means. The focus still seems to be on the perspective of 'fixing' the disability through therapies. ${ }^{38}$

Alongside this, parents voiced their desires relating to gait acquisition (walking) in the context of their comparison of their children with typical children. This is well documented in previous research with children with $\mathrm{CP}^{39}$ We know that many parents who have children who will never walk often still resist early introduction of mobility aids (such as adapted toy cars or wheelchairs). This is despite the fact that studies involving children with CP with severe motor impairment demonstrate very positive results when using these adaptations in terms of autonomy, self-esteem, social skills and participation. ${ }^{40}$ Recent studies have shown that promoting participation in children with physical disabilities can, in itself, result in improved body function and structure. ${ }^{41}$

Our findings also showed that parents concentrate on the child's impairments and that parents have high expectations for healing or a cure. Unfortunately, in Brazil, there is little acceptance of disabled children for what they are within their context. This negative view of disability is common for parents with children with similar conditions. ${ }^{42}$ Parents in Brazil tend to focus on their children's ability to perform daily activities as well as the environmental barriers at home, school and in the community. This demonstrates a need for action, including education, at a local and national level to change attitudes towards disability. One example which could be advocated is the use of accessible and open access educational tools such as MY ABILITIES FIRST. ${ }^{43}$

Our research has demonstrated what areas of the ICF parents of children with congenital infections such as CZS consider important. This information is vital to have 
when attempting to establish a COS for CZS. We also know that it is essential to also consider the child's own perspective as to what he/she considers to be relevant in outcome measures, however, children with CZS have limited communication and in our case, were not yet old enough to express their opinions.

We acknowledge that parents' perceptions of the needs of their children with CZS will change throughout their lives with further studies being necessary to understand this over time. Professionals will need to remain vigilant as scientific knowledge about the impact of CZS will evolve in the coming years. ${ }^{44}$ However, due to the similarity with $\mathrm{CP}$, many professionals working with these children in the early years are focusing on ways to provide devices to aid with functioning, stimulate child development, prevent worsening of health conditions and to support caregivers. Over time the focus will shift to supporting inclusion, independent living and to continuing to maintain health and function. ${ }^{36}$

There were a number of limitations in our study which must be taken into account. The sample was extracted from three Brazilian cities, from public or not-for profit rehabilitation centres. In this way, our findings may not represent the perspectives of all parents of children with CZS and should not be generalised. Our study generated the views of mothers predominantly with very few fathers taking part. Fathers may have a very different perspective and may have provided very different results to our study. Finally, within this study, we were unable to take the views of the children themselves into account. This would be important and relevant to consider in the future.

\section{CONCLUSION}

This is a unique study which aims to understand the views and perception of parents with regard to the needs of their children with CZS guided by the ICF. Although the parents did concentrate on issues related to movement abilities of their children, overall their emphasis was centred around environmental factors. These factors included services, systems and policies for prevention and treatment of their children as well as factors which would enable a healthy lifestyle to promote the physical and psychological well-being and social status of their children.

Our results reinforce the importance of including the parents' perspective in the development of a COS. Parents are the ones who live and experience the main limitations and potential of their children and in our study, they highlight the urgent need for environmental changes to improve the lives of children with CZS and their families in Brazil. In the future, when children with CZS are able to express their own opinions, we should also hear their views as to what they consider relevant for outcome measures.

\section{Author affiliations}

${ }^{1}$ Graduate Program in Collective, HealthFederal University of Rio Grande do Norte UFRN-FACISA, Natal, Brazil

${ }^{2}$ Division of Medical Sciences, University of Victoria, Victoria, British Columbia, Canada
${ }^{3}$ Department of Women and Children's Health, Institute of Translational Medicine, University of Liverpool, Liverpool, UK

${ }^{4}$ Instituto de Pesquisa Joaquim Amorim Neto, Campina Grande, Brazil

${ }^{5}$ Health of Women, Graduate Program in Rehabilitation Sciences, Federal University of Rio Grande do Norte - UFRN-FACISA, Santa Cruz, Brazil

${ }^{6}$ Health of Children, Graduate Program in Collective Health - Federal University of Rio Grande do Norte -UFRN-FACISA, Natal, Brazil

Acknowledgements The authors would like to thank all the participants who took part in this study: without them this study would not have been possible.This study was financed in part by the Coordenação de Aperfeiçoamento de Pessoal de Nível Superior - Brasil (CAPES) - Finance Code 001".

Contributors VS, MG and EL designed the study. TCC recruited the participants and conducted the interviews. VS, MG, EL and TCC reviewed and refined the data. TCC wrote the article. VS, MG, EL, MG, JST and AGM revised the article. TCC received qualitative research training through participation in a qualitative health research methods course at the Federal University of Rio Grande do Norte/Brazil.

Funding The authors have not declared a specific grant for this research from any funding agency in the public, commercial or not-for-profit sectors.

Competing interests None declared.

Patient and public involvement statement Families were not involved in the design, recruitment or conduct of the study. However, the results will be presented to families, professionals and managers at each participating centre, with a view to discussing strategies to meet the needs of children with CZS and their families.

Patient consent for publication Not required.

Ethics approval This research was approved by the Ethics and Research Committee of the Faculty of Health Sciences of Trairi/Federal University of Rio Grande do Norte (2.357.552), it was also reapproved at Liverpool University Ethics Committee (\#2083) and developed in three Brazilian rehabilitation centres for CZS in the states of Rio Grande do Norte (Physical Therapy School Clinic at UFRN-FACISA, in Santa Cruz) and Paraiba (Centre for the Care of Children with Microcephaly at the Professor Joaquim Amorim Neto Research Institute - IPESQ, in Campina Grande, and Physical Therapy School Clinic at UNIPE, in Joao Pessoa).

Provenance and peer review Not commissioned; externally peer reviewed.

Data availability statement Data are available on reasonable request from the corresponding author subject to restrictions to preserve anonymity and personal privacy. These data are not publicly available as they contain information that could compromise research participant privacy/consente.

Supplemental material This content has been supplied by the author(s). It has not been vetted by BMJ Publishing Group Limited (BMJ) and may not have been peer-reviewed. Any opinions or recommendations discussed are solely those of the author(s) and are not endorsed by BMJ. BMJ disclaims all liability and responsibility arising from any reliance placed on the content. Where the content includes any translated material, BMJ does not warrant the accuracy and reliability of the translations (including but not limited to local regulations, clinical guidelines, terminology, drug names and drug dosages), and is not responsible for any error and/or omissions arising from translation and adaptation or otherwise.

Open access This is an open access article distributed in accordance with the Creative Commons Attribution Non Commercial (CC BY-NC 4.0) license, which permits others to distribute, remix, adapt, build upon this work non-commercially, and license their derivative works on different terms, provided the original work is properly cited, appropriate credit is given, any changes made indicated, and the use is non-commercial. See: http://creativecommons.org/licenses/by-nc/4.0/.

ORCID iDs

Taynah Neri Correia Campos http://orcid.org/0000-0002-7647-0338

Melissa Gladstone http://orcid.org/0000-0002-2579-9301

\section{REFERENCES}

1 Rasmussen SA, Jamieson DJ, Honein MA, et al. Zika virus and birth defects - reviewing the evidence for causality. $N$ Engl J Med 2016;374:1981-7.

2 Krauer F, Riesen M, Reveiz L, et al. Zika virus infection as a cause of congenital brain abnormalities and Guillain-Barré syndrome: systematic review. PLoS Med 2017;14:e1002203. 
3 Mercado M, Ailes EC, Daza M, Reyes MM, et al. Zika virus detection in amniotic fluid and Zika-associated birth defects. Am J Obstet Gynecol 2020;222:610.e1-610.e13.

4 Pereira AM, Araujo Júnior E, Werner $\mathrm{H}$, et al. Zika virus and pregnancy: association between acute infection and microcephaly in newborns in the state of Rio de Janeiro, Brazil. Geburtshilfe Frauenheilkd 2020;80, :60-5.

5 Teixeira GA, Dantas DNA, Carvalho GAFdeL, et al. [Analysis of the concept of the Zika virus congenital syndrome]. Cien Saude Colet 2020;25, :567.

6 Oliveira Melo AS, Malinger G, Ximenes R, et al. Zika virus intrauterine infection causes fetal brain abnormality and microcephaly: tip of the iceberg? Ultrasound Obstet Gynecol 2016:47:6-7.

7 Melo ASdeO, Aguiar RS, Amorim MMR, et al. Congenital Zika virus infection: beyond neonatal microcephaly. JAMA Neurol 2016;73:1407-16.

8 Costello A, Dua T, Duran P, et al. Defining the syndrome associated with congenital Zika virus infection. Bull World Health Organ 2016;94:406.

9 Niemeyer B, Hollanda R, Muniz B, et al. What we can find beyond the classic neuroimaging findings of congenital Zika virus syndrome? Eur Neurol 2020;83:1-8.

10 MacDonald PDM, Holden EW, Wayne Holden E. Zika and public health: understanding the epidemiology and information environment. Pediatrics 2018;141:S137-45.

11 Ministério da Saúde (BR), Secretaria de Vigilância em Saúde. Vigilância em saúde no Brasil 2003|2019: dA criação dA Secretaria de Vigilância em Saúde aos dias atuais. Bol Epidemiol 2019:50:1-154

12 Williamson P, Altman D, Blazeby J, et al. Driving up the quality and relevance of research through the use of agreed core outcomes. London, England: SAGE Publications, 2012: 17. 1-2.

13 Prinsen CAC, Vohra S, Rose MR, et al. Core outcome measures in effectiveness trials (COMET) initiative: protocol for an international delphi study to achieve consensus on how to select outcome measurement instruments for outcomes included in a 'core outcome set'. Trials 2014;15:247.

14 Schiariti V, Mâsse LC. Identifying relevant areas of functioning in children and youth with cerebral palsy using the ICF-CY coding system: from whose perspective? Eur J Paediatr Neurol 2014;18:609-17.

15 World Health Organization. International classification of functioning disability and health: ICF. Geneva: World Health Organization, 2001.

16 Schiariti V, Longo E, Shoshmin A, et al. Implementation of the International classification of functioning, disability, and health (ICF) core sets for children and youth with cerebral palsy: global initiatives promoting optimal functioning. Int J Environ Res Public Health 1899;15:1899.

17 Pope C, Mays N. Reaching the parts other methods cannot reach: an introduction to qualitative methods in health and health services research. BMJ 1995;311:42-5.

18 Kitzinger J. Qualitative research. introducing focus groups. BMJ 1995;311:299-302.

19 Silva DBR, Pfeifer LI, Funayama CAR. Gross Motor Function Classification System Expanded \& Revised (GMFCS E \& R): reliability between therapists and parents in Brazil. Braz $J$ Phys Ther 2013:17:458-63.

20 Schiariti V, Sauve K, Klassen AF, et al. 'He does not see himself as being different': the perspectives of children and caregivers on relevant areas of functioning in cerebral palsy. Dev Med Child Neurol 2014;56:853-61.

21 Takahashi T, Okochi J, Kostanjsek N. Development of ICF illustration library. Tokyo Japan: WHO-Family of International Classifications Network Meeting, 2005.

22 Glegg SMN. Facilitating interviews in qualitative research with visual tools: a typology. Qual Health Res 2019;29:301-10.
23 Cieza A, Fayed N, Bickenbach J, et al. Refinements of the ICF linking rules to strengthen their potential for establishing comparability of health information. Disabil Rehabil 2019;41, :574-83.

24 Letts L, Wilkins S, Law M, et al. Guidelines for critical review form: qualitative studies (version 2.0). Hamilton: McMaster University Occupational Therapy Evidence-Based Practice Research Group, 2007.

25 Longo E, de Campos AC, Schiariti V. Zika virus after emergency response: can the ICF guide rehabilitation of children with microcephaly? Pediatr Phys Ther 2019;31:370-2.

26 Kuper H, Smythe T, Duttine A. Reflections on health promotion and disability in low and middle-income countries: case study of ParentSupport programmes for children with congenital Zika syndrome. Int $J$ Environ Res Public Health 2018;15:514.

27 Smythe T, Duttine A, Vieira ACD, et al. Engagement of fathers in parent group interventions for children with congenital Zika syndrome: a qualitative study. Int J Environ Res Public Health 2019;16, :3862.

28 Sá MRCde, Vieira ACD, Castro BSM, et al. [The need to act together in every way possible: inter-sector action in health and education for children living with the congenital Zika syndrome]. Cad Saude Publica 2019;35:e00233718.

29 Darrah J, Law MC, Pollock N, et al. Context therapy: a new intervention approach for children with cerebral palsy. Dev Med Child Neurol 2011;53, :615-20.

30 Duarte JdosS, Santos LOF, Sette GCS, et al. Necessidades de crianças CoM síndrome congênita pelo Zika vírus no contexto domiciliar. Cadernos Saúde Coletiva 2019;27:249-56.

31 Karadag Saygi E, Giray E, Peynirci Cersit H, et al. Assessment of family environment and needs of families who have children with cerebral palsy. Turk J Phys Med Rehabil 2015;61:320-5.

32 Adebanjo T, Godfred-Cato S, Viens L, et al. Update: interim guidance for the diagnosis, evaluation, and management of infants with possible congenital Zika virus infection-United States, October 2017. MMWR Morb Mortal Wkly Rep 2017;66:1089-99.

33 Broussard CS, Shapiro-Mendoza CK, Peacock G, et al. Public health approach to addressing the needs of children affected by congenital Zika syndrome. Pediatrics 2018;141:S146-53.

34 Freitas PSS, Soares GB, Mocelin HJS, et al. How do mothers feel? life with children with congenital Zika syndrome. Int J Gynecol Obstet 2020;148:20-8

35 Albuquerque MSV, Lyra TM, Melo APL, et al. Access to healthcare for children with congenital Zika syndrome in Brazil: perspectives of mothers and health professionals. Health Policy Plan 2019;34, :499-507.

36 Duttine A, Smythe T, Ribiero Calheiro de Sá M, et al. Congenital Zika Syndrome-Assessing the need for a family support programme in Brazil. Int J Environ Res Public Health 2020;17:3559.

37 Longo E, de Campos AC, Palisano RJ. Let's make pediatric physical therapy a true evidence-based field! can we count on you? Braz J Phys Ther 2019;23:187-8.

38 Rosenbaum P. The importance of context: what are our assumptions about childhood disability? Dev Med Child Neurol 2015;57:1084.

39 Vargus-Adams JN, Martin LK. Domains of importance for parents, medical professionals and youth with cerebral palsy considering treatment outcomes. Child Care Health Dev 2011;37, :276-81.

40 Martin MR, Dischino M. Go baby go! the freedom of movement. Palaestra 2017;31:14-17.

41 Imms C, Granlund M, Wilson $\mathrm{PH}$, et al. Participation, both a means and an end: a conceptual analysis of processes and outcomes in childhood disability. Dev Med Child Neurol 2017;59:16-25.

42 Dunn N, Shields N, Taylor NF, et al. Comparing the self concept of children with cerebral palsy to the perceptions of their parents. Disabil Rehabil 2009;31:387-93.

43 Schiariti V. My abilities first: positive language in health care. Clin Teach 2020;17:272-4.

44 Porter S, Mimm N. Infants with congenital Zika virus infection. Infants \& Young Children 2017;30:17-27. 